Revista de Ciencias Sociales - Número 68 (2016) - Páginas 155-174

Notas sobre la tramitación digital de los procedimientos judiciales...

\title{
NOTAS SOBRE LA TRAMITACIÓN DIGITAL DE LOS PROCEDIMIENTOS JUDICIALES TRAS LA IRRUPCIÓN DE LA LEY 20.886/2015
}

\author{
NOTES ON DIGITAL PROCESSING OF JUDICIAL \\ PROCEDURES AFTER ACT 20.886/2015
}

\author{
SEM SANDOVAL REYES* \\ Universidad de Valparaíso (Chile) \\ ssr@mackaycia.cl
}

\section{Resumen}

Para efectos de conseguir una mejor comprensión en torno a la tramitación digital de los procedimientos judiciales que entrará en vigor durante el año 2016, nos concentramos en la sistematización de la ley $\mathrm{N}^{\circ} 20.886 / 2015$, que la establece, refiriéndonos a los auto acordados $\mathrm{N}^{\text {os }} 54$ 2015 y 37-2016 de la Corte Suprema, sólo en cuanto se relacionan con la ley precitada. De esta manera se pretende suplir el vacío que pudiera producirse en aquellos estudiantes de Derecho que en el tránsito hacia la culminación

* Abogado, Licenciado en Ciencias Jurídicas, Universidad de Valparaíso. Profesor ayudante de Derecho procesal, Escuela de Derecho, Universidad de Valparaíso, Chile. Dirección: Errázuriz 2120, Valparaíso, Chile. Este trabajo está dedicado a los estudiantes del curso de Derecho procesal civil: procedimientos declarativos, primer semestre del año 2016, paralelo del profesor Lionel González G. y el suscrito. Artículo recibido el 13 de mayo de 2016 y aceptado el 30 de junio de 2016.

Revista de Ciencias Sociales - Número 68 (2016) - Universidad de Valparáíso - ISSN 0716-7725-Valparáiso, Chile 
de sus estudios, vieron reformado el cuerpo legal que sirvió de base a sus respectivas lecciones de Derecho procesal y hacer frente a la nueva manera en que deberán tramitarse los procedimientos civiles ante los Juzgados de Letras en lo Civil.

\section{Palabras clave}

Tramitación digital, procedimientos, judiciales.

\section{Abstract}

In order to obtain a better understanding of the new regulation of the handling of digital judicial proceedings which will come into effect during year 2016, we focus on the systematization of Law $\mathrm{N}^{\circ} 20.886 / 2015$, which established such procedure. We will only make reference to the Court Ordinances (Auto acordados) N54-2015 and No37-2016 issued by the Supreme Court so long as they have a relationship with said law. In this way, we intend to fill the gap that may affect those Law students who saw the rules of the Code of Civil Procedure studied in their course of Procedural law changed when they were about to conclude their studies, so that they have a source to understand the new way civil proceedings will be handled before the Civil Courts.

\section{Keywords}

Digital judicial proceedings, procedure, judicial.

\section{Introducción}

La ley $\mathrm{N}^{\circ} 20.886 / 2015$ (o indistintamente, "ley $\mathrm{N}^{\circ} 20.886$ "), reforma el Código de Procedimiento Civil (en adelante CPC) y otros cuerpos normativos que son fuente de Derecho procesal, en un aspecto de trascendencia general: la tramitación digital de los diferentes procedimientos que en dicho cuerpo legal se regulan, especialmente los declarativos y ejecutivos. Esta iniciativa encontró su epicentro en el propio poder judicial, con el auto acordado (en adelante AA) $\mathrm{N}^{\circ} 54$ 2014 de la Corte Suprema, incorporándose por último, el reciente AA $\mathrm{N}^{\circ}$ 37-2016, también del máximo tribunal, todos los cuales son relevantes a la hora de tratar la tramitación digital de los procedimientos judiciales.

Facultad de Derecho y Ciencias Sociales - Universidad de Valparaíso - Chile 
En el tránsito hacia su implementación completa se han planteado dos problemas que sirven de fundamento y objetivo a este trabajo: El primero, consiste en intentar suplir el eventual vacío que pudiera producirse en aquellos estudiantes de Derecho que en el tránsito hacia la culminación de sus estudios, han visto reformado el cuerpo legal que sirvió de base a sus respectivas lecciones de Derecho procesal. El segundo, dice relación con la praxis, donde se constata especialmente en los Juzgados de Letras en lo Civil, que existe una colisión entre el nuevo sistema y aquellos operadores jurídicos que en forma centenaria trataron con el órgano jurisdiccional de una manera diferente, percibiéndose la reforma como teóricamente perfecta, pero impracticable apenas apartadas del escritorio las hojas que la contienen.

Para efectos de dimensionar su impacto (simbólico por lo menos), sirve observar que esta reforma defenestra del proceso civil al mítico expediente de papel. Su cenit tendrá lugar con la vigencia de esta ley, es decir, a mediados y fines del año 2016, por medio de una implementación parcelada por zonas geográficas del país.

Considerando que la ley 20.886, fue concebida en su cuerpo de manera muy engorrosa, lo que se torna mucho más dificultoso a la hora de integrarla con los AA, y que no existe aún un trabajo de sistematización que torne más comprensible el fenómeno, nos hemos dado a la tarea, especialmente pensando en los estudiantes de Derecho procesal de la Escuela de Derecho de la Universidad de Valparaíso, procurando utilizar un método que pedagógicamente resulte familiar.

Sin más pretensión que la pedagógica entonces, nos referimos a continuación a los principales cambios que esta ley trae consigo, sin perjuicio de algunos aspectos de los AA 54-2015 y 37-2016 de la Corte Suprema, cuando resulte pertinente, especialmente en los rubros sobre la formación del expediente, las actuaciones judiciales ${ }^{1}$, y algunos

1. Sobre estos aspectos antes de la reforma, pueden consultarse algunos de los siguientes manuales: STOEHREL MAES, Carlos: De las disposiciones comunes a todo procedimiento y de los incidentes. Editorial Jurídica de Chile, Santiago, 2015 ( $6^{\mathrm{a}}$. Ed.). Pág. 21-34, 61-73; 81-94; FIGUEROA YÁVAR, Juan; MORGADO SAN MARTÍN, Erika: Jurisdicción, competencia y disposiciones comunes a todo procedimiento. Editorial Legalpublishing/Thomson Reuters, Santiago, 2013. Pág. 218-241, 265-270; CASARINO VITERBO, Mario: Manual de Derecho procesal (Derecho procesal civil). 
aspectos propios de la prueba documental electrónica y los recursos, que deben tenerse especialmente presente al momento de instar por la tramitación digital de los procedimientos judiciales.

Consignamos finalmente, que en nuestra opinión, a esta reforma se la comprende mejor si se la observa en su genuino sentido, es decir, constituir un intento por mejorar la gestión de la tramitación de causas por el poder judicial, compartiendo, por ende, lo expuesto por la Corte Suprema al informar el proyecto de ley: que esta reforma no implica una alteración a la naturaleza escrita de los procedimientos ni a la organización y atribuciones de los tribunales de justicia.

Se resta credibilidad, en consecuencia, a los otros propósitos declarados en su historia, como constituir una "antesala a la reforma procesal civil", el "abaratamiento de costos" (fundamentalmente para el Estado), el "generar una mayor cercanía de los justiciables con nuestro arcaico sistema de justicia civil”, "establecer una litigación responsable por parte de los abogados", protección del "medio ambiente", etc. ${ }^{2}$.

En cualquier caso, esta ley no puede transformarse en un óbice ni en una excusa para dejar de imprimir prisa a la reforma a la justicia civil actualmente en discusión en los órganos que conforman nuestro legislativo.

\section{Aspectos medulares de la ley 20.886 sobre tramitación digital de procedimientos judiciales}

\section{1. Ámbito de aplicación de la ley}

Esta ley se aplicará a todas las causas que conozcan los tribunales ordinarios y especiales que integran el poder judicial, con excepción de

Editorial Jurídica de Chile, Santiago, 2007 (6ª . Ed., t. 3), Pág. 71-120; QUEZADA MELÉNDEZ, José. Disposiciones comunes a todo procedimiento. Ediciones Digesto Ltda., Santiago, 1999. Pág. 167-179; PÉREZ RAGONE, Álvaro; NÚÑEZ OJEDA, Raúl: Manual de Derecho procesal civil. Parte general. Editorial LegalPublishing/ Thomson Reuters, Santiago 2013. Págs. 383-455.

2. Cfr. Historia de la Ley 20.886/2015, pp. 3-7, 17, disponible en: http://www. bcn.cl/historiadelaley/fileadmin/file_ley/4681/HLD_4681_37a6259cc0cldae 299a7866489dff0bd.pdf

Facultad de Derecho y Ciencias Sociales - Universidad de Valparaíso - Chile 
las causas que conozcan los tribunales militares en tiempos de paz (art. $1^{\circ}$ ley $\left.\mathrm{N}^{\circ} 20.886\right)$.

Los tribunales son: la Corte Suprema, las Cortes de Apelaciones, los Presidentes y Ministros de Cortes, los Tribunales de Juicio Oral en lo Penal, los Juzgados de Garantía. También, los Juzgados de Familia, los Juzgados de Letras del Trabajo, los Juzgados de Cobranza Laboral y Previsional, y los Juzgados de Letras en lo Civil.

En virtud del artículo $2^{\circ}$ transitorio de la ley, sólo se aplicará a causas iniciadas con posterioridad a su entrada en vigencia, para lo cual se atenderá a la fecha de la demanda o medida prejudicial.

\subsection{Principios generales relativos a la tramitación digital}

\section{a) Principio de equivalencia funcional del soporte electrónico}

El principio básico que sirve de pilar a los demás, se denomina por la ley de equivalencia funcional del soporte electrónico. En síntesis, consiste en que un acto procesal sólo será válido y producirá los mismos efectos que produciría en soporte de papel, si es suscrito por medio de firma electrónica (art. $2^{\circ}$ letra a) ley 20.886).

La idea central de los siguientes cuatro principios que se contemplan en la ley y que se expondrán sintéticamente a continuación, apuntan en nuestra opinión, al correcto funcionamiento del sistema informático del órgano jurisdiccional y lo que se denomina carpeta electrónica, por medio de la cual se reemplaza el antiguo artículo 29 CPC, referido al expediente de papel.

El artículo 29 CPC reformado sostiene que: "se formará la carpeta electrónica con los escritos, documentos, resoluciones, actas de audiencias y actuaciones de toda especie que se presenten o verifiquen en el juicio (...)" la que deberá, por regla general, encontrarse disponible en el portal de internet del poder judicial.

\section{b) Principios de fidelidad y actualización}

En virtud del principio de fidelidad, los actos procesales deben registrarse y conservarse íntegramente en la carpeta electrónica, permitiendo reproducir su contenido.

Revista de Ciencias Sociales - Número 68 (2016) - Universidad de Valparáíso - ISSN 0716-7725-Valparaíso, Chile 
Dicha carpeta, a su vez, deberá ser actualizada por la Corporación Administrativa del poder judicial, en virtud del principio de actualización.

\section{c) Principio de cooperación}

A objeto de instar por la operatividad del sistema, los órganos jurisdiccionales, auxiliares de la administración de justicia y en general, las instituciones públicas, deben dar cumplimiento al principio de cooperación, en el sentido de reconocer recíprocamente los documentos electrónicos que emanen de cada uno, así como los medios de identificación y autenticación que correspondan.

\section{d) Principio de publicidad}

En virtud de este principio los actos de los tribunales son públicos. Además, se contempla el deber de garantizar a todas las personas en igualdad, el acceso a la carpeta electrónica.

Existen, sin embargo, presentaciones de las partes que sólo serán visibles una vez que se practique la respectiva notificación, estas son: las demandas, las medidas cautelares, las medidas prejudiciales precautorias y otras cuya eficacia requiera de la reserva, hasta la práctica de la notificación.

\section{e) Principio de buena fe}

En resguardo de todos los principios anteriores se impone el deber de actuar de buena fe a todos quienes intervengan en el juicio a través del sistema informático de tramitación. Por medio de aquél se vela por la integridad y correcto funcionamiento del propio sistema informático. También, se busca evitar el fraude o abuso procesal, la contravención de actos propios, u otra conducta ilícita o dilatoria (art. $2^{\circ}$ letras b), e) y f) ley 20.886).

Facultad de Derecho y Ciencias Sociales - Universidad de Valparaíso - Chile 


\subsection{La carpeta electrónica}

\section{a) Importancia}

Este es un aspecto central de la ley 20.886: la creación de la carpeta electrónica, que reemplaza al expediente de papel. Para el registro y conservación de los actos procesales, ahora electrónicos, en vez de aguja y el papel, se dispone la utilización de "cualquier medio que garantice la fidelidad, preservación y reproducción de su contenido". Por exigencia legal, la citada carpeta electrónica debe encontrarse disponible al público en el portal de internet del poder judicial (art. 29 CPC).

\section{b) Descripción de la carpeta electrónica}

La ley no define a la carpeta electrónica. Señala sólo la materia prima con que se forma y las características generales del medio en que deben registrarse y conservarse, según se adelantó en el acápite anterior.

El artículo $29 \mathrm{CPC}$, sostiene que "se formará carpeta electrónica con los escritos, documentos, resoluciones, actas de audiencias y actuaciones de toda especie que se presenten o verifiquen en el juicio". Se sostiene que "ninguna pieza de la carpeta electrónica podrá eliminarse sin que previamente lo decrete el tribunal que conoce de la causa" (en este aspecto, la ley resulta coherente con el artículo primero del AA 54-2014).

c) Forma de incorporación de escritos, documentos y otros actos procesales a la carpeta electrónica

El artículo 30 CPC reformado, señala que "los escritos y documentos se presentarán por vía electrónica”. Las piezas se irán agregando en forma sucesiva y serán automáticamente foliadas por el propio sistema informático. Ya no será necesario acompañar junto con cada escrito copias para la contraparte.

Regla general: presentación a través del sistema de tramitación electrónica del poder judicial

Para la presentación de los escritos judiciales, el artículo $5^{\circ}$ inciso $1^{\circ}$ de la ley 20.886, sostiene como regla general, que los abogados y 
habilitados en Derecho, deberán registrarse en los plazos que señale la Corte Suprema mediante auto acordado, en un sistema de tramitación electrónica del poder judicial.

Es por medio de dicho sistema de tramitación en que deberán presentarse los escritos judiciales, lo que rige incluso respecto de las demandas.

Esta misma regla general opera para los documentos electrónicos, dejando abierta la posibilidad "en caso de requerirlo las circunstancias", para que se acompañen al tribunal mediante algún dispositivo de almacenamiento de datos electrónicos (art. 6 inciso $1^{\circ}$ ley 20.886).

Excepción: presentación en formato de papel y por medios distintos al sistema de tramitación electrónica del poder judicial.

La ley 20.886, contempla en su artículo 5 incisos 2 y 3, la posibilidad de presentación al tribunal de escritos en formato de papel. Las hipótesis para la excepción son dos: "cuando las circunstancias así lo requieran" o "se trate de una persona autorizada por el tribunal por carecer de medios tecnológicos necesarios".

En estos casos los escritos se entregarán por conducto del "ministro de fe respectivo o del buzón especialmente habilitado al efecto", los que deben ser digitalizados e incorporados a la carpeta electrónica, según la ley, "inmediatamente" después de presentados.

En el caso de los documentos cuyo formato original no sea el electrónico, lo que incluye a los títulos ejecutivos, el artículo 6 inciso $2^{\circ}$ de la ley 20.886, sostiene que pueden presentarse directamente al tribunal, donde quedarán bajo la custodia del ministro de fe o funcionario correspondiente, lo que sin embargo, no libera a la parte de acompañar una copia en formato digital de los mismos, por una de las siguientes vías: el sistema de tramitación electrónica del poder judicial o, la entrega de un dispositivo de almacenamiento de datos electrónicos.

Debe tenerse presente, sin embargo, que en el caso de los procedimientos ejecutivos, los títulos que les sirven de base que consten en formato de papel, deben ser presentados en el tribunal, bajo apercibimiento de tenerse por no iniciada la ejecución.

Por medio del art. $3^{\circ}$ del AA N³7-2016, la Corte Suprema profundizó este punto regulando la figura de la oficina judicial virtual, compuesta "(...) por un conjunto de servicios entregados en el portal de internet del poder judicial (...)”.

\footnotetext{
Facultad de Derecho y Ciencias Sociales - Universidad de Valparaíso - Chile
} 
La relevancia para el tema que tratamos estriba en lo siguiente: la presentación de escritos y documentos deberá tener lugar ante esta oficina, a la que sólo podrán acceder los usuarios que cuenten con una clave única del Estado, que debe ser proporcionada por el Servicio de Registro Civil e Identificación, entendiéndose para estos efectos como firma electrónica simple.

Consignamos finalmente, que en lo tocante a los procedimientos ejecutivos, es especialmente relevante el AA 54-2015, por dedicar gran parte de su regulación a dicha materia.

\section{d) Conservación y respaldo de los actos procesales}

El respaldo de los actos procesales es sólo informático, y debe tener lugar en forma periódica por el propio órgano jurisdiccional a través de la Corporación Administrativa de Poder Judicial.

\section{e) Pérdida y recuperación del registro electrónico de actos procesales}

De resultar dañado el registro electrónico, se dispone que debe ser reemplazado por una copia fiel electrónica. En tal caso, debe preferirse la copia fiel electrónica que pueda provenir del tribunal antes que aquella que pueda obtenerse de otra fuente.

Si no existe copia fiel, se impone al tribunal el deber de dictar nuevamente las resoluciones judiciales perdidas y la reiteración de las actuaciones procesales, excepto aquellas que constituyan el antecedente de resoluciones conocidas o en fase de cumplimiento o ejecución.

\subsection{Cumplimiento del requisito general de las actuaciones judiciales de dejar constancia en el proceso}

Esta exigencia se cumple según el nuevo artículo $61 \mathrm{CPC}$, por medio de testimonio fidedigno en la carpeta electrónica. El dejar debido registro constituye un imperativo para el órgano jurisdiccional y los auxiliares de la administración de justicia.

Cuando en la actuación intervengan varias personas, se debe levantar un acta, la que después que es firmada por todas las partes,

Revista de Ciencias Sociales - Número 68 (2016) - Universidad de Valparáíso - ISSN 0716-7725-Valparaíso, Chile 
debe digitalizarse e incorporarse inmediatamente en la carpeta electrónica.

Un cambio importante es el que se produce a propósito de la autorización por el funcionario a quien corresponde dar fe o certificado del acto, pues sólo se lo considera esencial para la validez de la actuación cuando una ley expresamente lo disponga.

El antiguo precepto sostenía a secas y en sentido amplio, que dicha autorización era esencial para la validez de la actuación.

El nuevo inciso final del artículo $61 \mathrm{CPC}$, deja la puerta abierta para que puedan registrarse las audiencias en que participe el tribunal mediante audio, video u otro soporte tecnológico equivalente, el que debe ser agregado a la carpeta electrónica.

\subsection{Necesidad de suscripción mediante firma electrónica avanzada por el Tribunal y los auxiliares de la Administración de Justicia}

$\mathrm{El}$ art. $4^{\circ}$ ley 20.886, establece con carácter general que las resoluciones judiciales, y las actuaciones que realicen el secretario, el administrador del tribunal y los auxiliares de la administración de justicia deben ser suscritas por medio de firma electrónica avanzada, las que tienen un carácter personal y se prohíbe que sean compartidas.

En el caso de las resoluciones judiciales, la firma electrónica avanzada del juez sustituye la autorización del funcionario llamado por ley a dar fe o certificado del acto, constituyendo una excepción a lo dispuesto por el artículo 61 inciso final CPC.

$\mathrm{El}$ artículo $4^{\circ}$ inciso $3^{\circ}$ ley 20.886 , señala expresamente que "las resoluciones suscritas por los jueces mediante firma electrónica avanzada, no requerirán de la firma ni de la autorización del ministro de fe correspondiente".

En torno al concepto de firma electrónica avanzada, la ley No 19.799/2002, sobre documento electrónico, firma electrónica y servicios de certificación de dicha firma, es pertinente el artículo $2^{\circ}$ letra g), que la define en síntesis como: "aquella certificada por un prestador acreditado, que ha sido creada usando medios que el titular mantiene bajo su exclusivo control (...)".

\footnotetext{
Facultad de Derecho y Ciencias Sociales - Universidad de Valparaíso - Chile
} 


\subsection{Cambios a propósito de la tramitación de exhortos, oficios y comunicaciones judiciales ${ }^{3}$}

Los arts. 10 y 11 de la ley 20.886, contemplan normas relativas a los exhortos nacionales, reconociendo formalmente, las categorías de oficios y comunicaciones judiciales a instituciones públicas nacionales.

Como común denominador se impone la utilización y tramitación a través de mecanismos electrónicos.

En el caso de los exhortos debe utilizarse prioritariamente el sistema de tramitación electrónica del poder judicial, en subsidio, frente a la ausencia de dicho recurso técnico, debe utilizarse una casilla de correo electrónico especialmente creada para tal efecto o el medio de comunicación idóneo más eficaz de que disponga el tribunal.

En el caso de los oficios y comunicaciones judiciales a instituciones públicas nacionales, el matiz del precepto es diferente, ordenando su diligenciamiento por medios electrónicos o en subsidio, el medio de comunicación idóneo más eficaz de que disponga esa institución pública.

\subsection{Cambios a propósito de notificaciones ${ }^{4}$ :}

\section{a) Esta ley crea el estado diario electrónico, que debe estar disponible diariamente en la página web del poder judicial}

Se establece expresamente un supuesto de nulidad procesal: la notificación por el estado diario electrónico será nula si no se puede visualizar la resolución por problemas técnicos, la que puede ser declarada de oficio o a petición de parte.

3. Refiriéndose al tema en el acápite denominado "competencia y la cooperación o asistencia judicial”: ROMERO SEGUEL, Alejandro. Curso de Derecho procesal civil. Los presupuestos procesales relativos al órgano jurisdiccional y a las partes. LegalPublishing/Thomson Reuters, Santiago, 2014 (2 ${ }^{\text {a }}$ Ed., tomo 2). Págs. 82-83.

4. Un manual muy útil sobre el tema, sin perjuicio de las obras generales ya citadas: CAMIRUAGA CHURRUCA, José: De las notificaciones. Editorial Jurídica de Chile, Santiago, 1995 (3ª. Ed.). Págs. 9-382. 


\section{b) Notificación electrónica}

Esta ley contempla en el artículo 8, la posibilidad de que las partes propongan para sí una forma de notificación electrónica. El tribunal calificará su eficacia y que no causa indefensión. Una vez admitida, será válida para todo el proceso.

El precepto legal resulta problemático al sostener que esta forma de notificación podrá ser aceptada por el tribunal, "aun cuando la ley disponga que la notificación deba realizarse por cédula”.

El problema de esta forma de notificación consiste, en que según el tenor de la norma, las resoluciones se entenderán notificadas electrónicamente aun cuando la ley exija notificación por cédula, lo que puede aparejar problemas en la tramitación de los casos complejos, en que las constantes estratégicas de litigación de las partes generalmente consisten en poder alternar períodos de ataque y defensa, junto con espacios sin actividad. Adoptada ahora la notificación electrónica por la parte, no existirá dicha posibilidad, sumiéndose el proceso en una espiral de sucesivo avance, con detenciones sólo excepcionales.

\section{c) Mayores exigencias para los receptores judiciales, imperativo de incluir registro georreferenciado, fotografías o video al registro de sus actuaciones}

En primer término, en virtud del artículo 9 inciso $1^{\circ}$ ley 20.886, los receptores judiciales deben encontrase registrados en el sistema de tramitación electrónica del poder judicial.

Dentro del plazo de dos días hábiles, deben incorporar a la carpeta electrónica un testimonio que dé cuenta de la actuación que se realizó, con constancia de todo lo obrado.

Las mayores exigencias que impone la ley en este sentido, son las siguientes:

Primero: A propósito de cada notificación que practiquen los receptores judiciales, los requerimientos o embargos, deben incluir en su certificación un registro georreferenciado que indique el lugar, fecha y hora en que se realizó la actuación.

Facultad de Derecho y Ciencias Sociales - Universidad de Valparaíso - Chile 
El artículo $5^{\circ}$ del AA 37-2016 de la Corte Suprema, sostiene que la georreferenciación debe realizarse usando un programa computacional o aplicación móvil que la Corporación Administrativa del Poder Judicial debe poner a disposición de los receptores judiciales, quienes deberán contar con dispositivos móviles que permitan la descarga de aplicaciones y cuenten con cámara y sistema de georreferenciación.

Segundo: más aún, tratándose del retiro de especies, deben incluir un registro fotográfico o de video con fecha y hora, de los bienes muebles al momento del retiro para su entrega al martillero, salvo que el deudor o el depositario se opongan.

Tercero: el receptor judicial que no cumpla con estas exigencias de manera dolosa o incluso culpable, incurrirá en una falta que se considerará como grave, y que puede ser sancionada disciplinariamente por el órgano jurisdiccional, previa audiencia del afectado (arts. 9 inc. 3, 4, 5 ley 20.886 y 532 inciso $3^{\circ}, \mathrm{N}^{\text {os }} 2,3$ y 4 COT).

\subsection{Resoluciones judiciales}

\section{a) Firma de las resoluciones judiciales}

El nuevo artículo 169 CPC, sostiene que toda resolución, de cualquier clase que sea, deberá llevar al pie, la firma electrónica avanzada del juez o jueces que la dicten o intervengan en el acuerdo.

\section{b) Situación de las llamadas "sentencias definitivas parciales"}

El artículo 172 CPC, señala que cuando en un juicio se ventilen dos o más cuestiones que puedan ser resueltas separada o parcialmente, sin que ello ofrezca dificultad para la marcha del proceso, y alguna o algunas de dichas cuestiones o parte de ellas, lleguen al estado de sentencia antes de que termine el procedimiento en las restantes, podrá el tribunal fallar desde luego las primeras.

En este caso, se formará cuaderno electrónico separado con las piezas necesarias para dictar fallo y ejecutarlo.

Revista de Ciencias Sociales - Número 68 (2016) - Universidad de Valparáíso - ISSN 0716-7725-Valparaíso, Chile 
c) Mayores potestades para los secretarios abogados de los Juzgados de Letras en lo civil

Antes de la reforma, los secretarios letrados de los Juzgados de Letras en lo civil podían sólo dictar decretos. El nuevo artículo 33 CPC en cambio, permite que puedan dictar sentencias interlocutorias, autos y decretos, salvo cuando puedan poner término al juicio o hacer imposible su continuación. El recurso de reposición que se interponga por la parte en contra de dichas resoluciones, debe ser resuelto por el juez.

\subsection{Postulación procesal}

De manera complementaria a la ley $\mathrm{N}^{\circ} 18.120$ sobre comparecencia en juicio, el art. $7^{\circ}$ de la ley 20.886 , incorpora una nueva manera de constituir el patrocinio y mandato judicial, mediante la utilización de firma electrónica avanzada. Según el tenor literal de la ley, estas nuevas formas resultan complementarias a las que ya existen en nuestro sistema.

Respecto del patrocinio, a partir de la vigencia de la ley, podrá constituirse mediante la sola utilización de firma electrónica avanzada, debiendo el propio órgano jurisdiccional, a través de sus registros, constatar la calidad de abogado del suscriptor.

Por su parte, para constituir el mandato judicial bastará la declaración escrita del mandante suscrita mediante firma electrónica avanzada, sin que se requiera su presencia ante el ministro de fe para autorizar su representación.

\section{Incidencia de la ley $\mathbf{N}^{\circ} \mathbf{2 0 . 8 8 6}$ en la prueba documental electrónica} y los recursos: derogación de cargas procesales

\subsection{Normas en torno a la prueba documental electrónica}

El documento electrónico ha significado para el CPC una doble reforma. En primer lugar, aquella que tuvo lugar por medio de la ley 20.217/2007, que incorporó el art. 348 bis ; y luego, la que se introduce

5. Una explicación del fenómeno hasta antes de la irrupción de la ley 20.886 en Chile, se encuentra en BORDALÍ SALAMANCA, Andrés; CORTEZ

Facultad de Derecho y Ciencias Sociales - Universidad de Valparaíso - Chile 
por medio de la ley objeto de comentario, que la contrarreforma en lo tocante a la audiencia de percepción documental.

En virtud de su diseño original, esta prueba documental electrónica se producía sólo por medio de una audiencia de percepción del documento electrónico, a la que debían ser citadas las partes por y ante el tribunal, salvo que los documentos no pudieran ser transportados, en cuyo caso, debía celebrarse en el lugar donde se encontraran los documentos electrónicos.

La ley 20.886, introduce un nuevo inciso final al artículo 348 bis CPC, según el cual: "en el caso que los documentos electrónicos acompañados puedan ser percibidos directamente en la carpeta electrónica, el tribunal podrá omitir la citación a audiencia de percepción, debiéndose entender que han sido puestos en conocimiento de la parte contraria desde que se notifica la resolución que los tiene por acompañados bajo el apercibimiento correspondiente".

Por lo tanto, la audiencia de percepción documental, sólo deberá tener lugar en las siguientes dos hipótesis: a) si el documento electrónico no puede ser acompañado al tribunal; caso en el cual, la audiencia se celebrará donde los documentos se encuentren; b) si el documento electrónico es acompañado al tribunal, pero no puede ser percibido directamente en la carpeta electrónica; caso en el cual, la audiencia deberá tener lugar en las dependencias del órgano jurisdiccional.

\subsection{Normas relativas a recursos}

Los recursos en los que tiene incidencia la ley que se comenta en este trabajo son los siguientes: el recurso de apelación, el recurso de

MATCOVICH, Gonzalo; PALOMO VÉLEZ, Diego: Proceso civil. El Juicio ordinario de mayor cuantía, procedimiento sumario y tutela cautelar. Editorial LegalPublishing/ Thomson Reuters, Santiago, 2014 (2da. Ed.). Pág. 326-329; PÉREZ RAGONE, Álvaro; NÚNEZ OJEDA, Raúl: Manual de Derecho procesal civil. Proceso ordinario de mayor cuantía. Editorial LegalPublishing/Thomson Reuters, Santiago, 2014. Págs. 180-181; OBERG YÁÑEZ, Héctor: "Un desastre procesal (documento electrónico Arts. 342 $\mathrm{N}^{\circ} 6$ - 348 bis C.P.C.)”. En: Revista actualidad jurídica, Facultad de Derecho, Universidad del Desarrollo, $\mathrm{N}^{\circ} 18,2008$. Págs. 239-245.

Revista de Ciencias Sociales - Número 68 (2016) - Universidad de Valparáíso - ISSN 0716-7725-Valparáiso, Chile 
hecho y los recursos de casación en la forma y en el fondo ${ }^{6}$, excluyéndose de nuestro análisis sólo lo relativo al recurso de hecho.

La nota distintiva consiste en la eliminación de cargas procesales que surgían con posterioridad a la concesión del recurso por el tribunal a quo, cuyo incumplimiento aparejaba su terminación anticipada y diferente al conocimiento y resolución por el tribunal ad quem. En lo restante, el ajuste realizado resulta coherente con un procedimiento que pretende suplir el soporte de papel por otro de carácter digital.

a) Cambios en relación con el recurso de apelación Eliminación de la carga procesal consistente en depósito de fondos suficientes para la confección de compulsas o fotocopias

Se elimina para el apelante de un recurso de apelación concedido en el sólo efectivo devolutivo la carga procesal consistente en la consignación de fondos necesarios para la confección de compulsas o fotocopias.

En virtud del nuevo artículo 197 CPC, una vez que se conceda un recurso de apelación el tribunal a quo deberá remitir electrónicamente al tribunal ad quem, copia fiel de la resolución apelada, del recurso y de todos los antecedentes que fueren pertinentes para el conocimiento y fallo del recurso.

Eliminación de la carga procesal de comparecer ante el tribunal superior a seguir el recurso interpuesto ("hacerse parte"), y por ende de la deserción del recurso de apelación por dicho motivo

Una vez recibido el recurso, el tribunal ad quem, junto con certificar la fecha de la recepción de los antecedentes por el tribunal $a$

6. En su versión anterior a la reforma, pueden consultarse: MOSQUERA RUIZ, Mario; MATURANA MIQUEL, Cristián: Los recursos procesales. Editorial Jurídica de Chile, Santiago, 2010, Pág. 162-176, 214-221; 223-230; 268-272; 312-318; TAVOLARI OLIVEROS, Raúl: Recursos de casación y queja. Nuevo régimen. Editorial Jurídica Conosur Ltda., Santiago, 1996. Págs. 45-88; CASARINO VITERBO, Mario: Manual de Derecho procesal (Derecho procesal civil). Editorial Jurídica de Chile, Santiago, 2007 (6a. Ed., t.6). Págs. 133-215. Una de las últimas obras sobre la materia, con una propuesta diferente: ROMERO SEGUEL, Alejandro, El recurso de casación en el fondo civil. Propuesta para la generación de precedentes judiciales. Editorial LegalPublishing/ Thomson Reuters, Santiago, 2013. Págs. 1-207.

Facultad de Derecho y Ciencias Sociales - Universidad de Valparaíso - Chile 
quo, debe asignarle un número de ingreso (art. 200 CPC). Sólo en el caso de recursos de apelaciones concedidos en el sólo efecto devolutivo debe procederse a la apertura de un cuaderno electrónico separado para su conocimiento y fallo, pues en el caso de los recursos concedidos en ambos efectos, debe proseguirse la tramitación del recurso en la misma carpeta electrónica del tribunal a quo.

Hacemos presente que si bien la ley al tratar esta materia en el artículo 197 CPC se refiere a "la Corte de Apelaciones", nosotros aludimos al tribunal ad quem, por su amplia aplicación.

Con la nueva ley, por tanto, se eliminan los siguientes motivos de terminación "anormal" del recurso de apelación: a) la deserción por no depositar fondos suficientes para la confección de fotocopias o compulsas y; b) no comparecer ante el tribunal ad quem a proseguir con la tramitación del recurso por medio de la presentación de un escrito "se hace parte".

\section{Se elimina la prescripción del recurso de apelación}

La ley 20.886, derogó el artículo 211 CPC, por el cual las partes no podían dejar transcurrir más de uno o tres meses, dependiendo de la naturaleza de la resolución impugnada, sin realizar gestión alguna para que el recurso interpuesto quedase en estado de fallarse por el tribunal ad quem, a objeto de evitar que como consecuencia de su inactividad, se solicitase por su contendor, que se declarase firme la resolución impugnada por haberse producido la prescripción del recurso.

\section{b) Cambios en relación con los recursos de casación en la forma y en el fondo Aplicación del artículo 197 inciso $1^{\circ}$ CPC, se elimina la deserción por no proveer de fondos suficientes para fotocopias o compulsas}

El nuevo art. $776 \mathrm{CPC}$, sostiene que una vez interpuesto el recurso de casación, el tribunal a quo debe realizar un control de admisibilidad en torno a haber sido interpuesta la impugnación dentro de plazo y patrocinada por abogado habilitado.

Si el recurso es declarado admisible, entonces, debe darse cumplimiento a lo que establece el nuevo art. 197 inc. $1^{\circ} \mathrm{CPC}$, es decir:

Revista de Ciencias Sociales - Número 68 (2016) - Universidad de Valparáíso - ISSN 0716-7725-Valparaíso, Chile 
el tribunal a quo, deberá remitir electrónicamente al tribunal ad quem copia fiel de la resolución casada, del recurso y de todos los antecedentes que fueren pertinentes para un acabado pronunciamiento.

Lo anterior, por cuanto se eliminó la referencia que el antiguo art. 776 CPC hacía a la necesidad de remitir los autos originales al tribunal superior para que conozca del recurso y de devolver las fotocopias o compulsas respectivas al tribunal que deba conocer del cumplimiento del fallo.

Como consecuencia de lo mismo, se exime al recurrente de la carga procesal de consignar fondos suficientes para la confección de fotocopias o compulsas, eliminando la consecuencia jurídica desfavorable derivada de su incumplimiento consistente en la deserción.

\section{Eliminación de la carga procesal de franquear la remisión del proceso}

Como directa consecuencia de la tramitación digital, la ley 20.886, expresamente deroga el art. 777 CPC, por el cual el recurrente de casación debía franquear la remisión del proceso, es decir, costear los fondos necesarios para el correo, cuya inobservancia permitía al contendor instar porque se requiriese a su contraparte recurrente para tal efecto, bajo apercibimiento de declarar el recurso como no interpuesto.

\section{Aplicación del nuevo artículo 200 CPC al recurso de casación en la forma y en el fondo}

El nuevo art. 779 CPC, a diferencia de su anterior versión, torna aplicable al recurso de casación sólo lo que establece el art. 200 CPC. Excluye la aplicación los artículos 201, 202, 211 del CPC.

Esto quiere decir, que el tribunal ad quem, una vez que recibe el recurso y los antecedentes del mismo, debe certificar en la carpeta electrónica la recepción y su fecha, eliminándose la carga del recurrente de comparecer ante el tribunal superior a seguir el recurso interpuesto, como también la sanción por incomparecencia del recurrido ante el tribunal ad quem, y la prescripción del recurso.

Facultad de Derecho y Ciencias Sociales - Universidad de Valparaíso - Chile 


\section{Palabras finales}

Al final de este trabajo esperamos haber satisfecho nuestras pretensiones iniciales, consistentes en tratar los principales aspectos que trae consigo la implementación de la tramitación digital de los procedimientos judiciales luego de la irrupción de la ley $\mathrm{N}^{\circ} 20.886$, que reforma el Código de Procedimiento Civil.

Esperamos ayudar a aquellos estudiantes de Derecho que en el tránsito hacia la culminación de sus estudios lo necesiten, sobre todo a quienes en tránsito hacia la titulación vieron reformado el cuerpo legal que sirvió de base a sus respectivas lecciones de Derecho procesal y, en la misma medida, a los operadores jurídicos que deberán tratar en la praxis con el nuevo sistema de tramitación judicial.

Esperamos haber demostrado que esta reforma apunta en rigor, a mejorar la gestión de la tramitación de causas en el seno del poder judicial, sin alterar en términos sustanciales la naturaleza escrita de los procedimientos ni a la organización y atribuciones de los tribunales de justicia y que en el mismo sentido, pueda compartirse nuestra concepción en torno a restar credibilidad a los otros propósitos declarados en la historia de la ley como justificación para su dictación, como constituir una "antesala a la reforma procesal civil", el "abaratamiento de costos" (fundamentalmente para el Estado), el "generar una mayor cercanía de los justiciables con nuestro arcaico sistema de justicia civil”, "establecer una litigación responsable por parte de los abogados", protección del “medio ambiente”, etcétera.

Reafirmamos finalmente nuestra postura: esta ley no puede transformarse en un óbice ni en una excusa para dejar de imprimir prisa a la reforma a la justicia civil actualmente en discusión en los órganos que conforman nuestro legislativo.

\section{BIBLIOGRAFÍA}

BORDALÍ SALAMANCA, Andrés; CORTEZ MATCOVICH, Gonzalo; PALOMO VÉLEZ, Diego: Proceso civil. El Juicio ordinario de mayor cuantía, procedimiento sumario y tutela cautelar. Editorial LegalPublishing/Thomson Reuters, Santiago, 2014 (2da. Ed.).

Revista de Ciencias Sociales - Número 68 (2016) - Universidad de Valparáíso - ISSN 0716-7725-Valparaíso, Chile 
CAMIRUAGA CHURRUCA, José: De las notificaciones. Editorial Jurídica de Chile, Santiago, 1995 (3ª . Ed.).

CASARINO VITERBO, Mario: Manual de Derecho procesal (Derecho procesal civil). Editorial Jurídica de Chile, Santiago, 2007 (6a. Ed., t. 6).

- Manual de Derecho procesal (Derecho procesal civil). Editorial Jurídica de Chile, Santiago, 2007 (6 $6^{\text {a }}$. Ed., t. 3).

FIGUEROA YÁVAR, Juan; MORGADO SAN MARTÍN, Erika: Jurisdicción, competencia y disposiciones comunes a todo procedimiento. Editorial Legalpublishing/Thomson Reuters, Santiago, 2013.

MOSQUERA RUIZ, Mario; MATURANA MIQUEL, Cristián: Los recursos procesales. Editorial Jurídica de Chile, Santiago, 2010.

OBERG YÁÑEZ, Héctor: "Un desastre procesal (documento electrónico Arts. $342 \mathrm{~N}^{\circ} 6-348$ bis C.P.C.). En: Revista actualidad jurídica, Facultad de Derecho, Universidad del Desarrollo, N 18, 2008. Págs. 239-245.

PÉREZ RAGONE, Álvaro; NÚÑEZ OJEDA, Raúl: Manual de Derecho procesal civil. Parte general. Editorial LegalPublishing/Thomson Reuters, Santiago 2013.

— Manual de Derecho procesal civil. Proceso ordinario de mayor cuantía. Editorial LegalPublishing/Thomson Reuters, Santiago, 2014.

QUEZADA MELÉNDEZ, José. Disposiciones comunes a todo procedimiento. Ediciones Digesto Ltda., Santiago, 1999.

ROMERO SEGUEL, Alejandro. Curso de Derecho procesal civil. Los presupuestos procesales relativos al órgano jurisdiccional y a las partes.

LegalPublishing/Thomson Reuters, Santiago, 2014 (2 ${ }^{\mathrm{a}}$ Ed., tomo 2).

_- El recurso de casación en el fondo civil. Propuesta para la generación de precedentes judiciales. Editorial LegalPublishing/Thomson Reuters, Santiago, 2013.

STOEHREL MAES, Carlos: De las disposiciones comunes a todo procedimiento y de los incidentes. Editorial Jurídica de Chile, Santiago, 2015 (6 . Ed.).

TAVOLARI OLIVEROS, Raúl: Recursos de casación y queja. Nuevo régimen. Editorial Jurídica Conosur Ltda., Santiago, 1996.

Facultad de Derecho y Ciencias Sociales - Universidad de Valparaíso - Chile 